\title{
A Comparative Double-Blind Randomized Clinical Trial Study on Effect of Various Analgesic Intravenous Injections on Propofol Post- injection Pain in Patients Undergoing Elective Surgery
}

\section{Hashem Jarineshin, Amineh Ahmadipour, Mehrdad Malekshoar, Majid Vatankhah*}

Department of Anesthesiology, Critical Care and Pain Management Research Center, Hormozgan University of Medical Sciences, Bandar Abbas, Iran.

Study Area: Bandar Abbas, Iran

Coordinates: $27^{\circ} 11^{\prime} \mathrm{N} ; 56^{\circ} 16^{\prime} \mathrm{E}$,

Key words: Paracetamol, Dexamethasone, Pethidine, Lidocaine, Ketamine

The study protocol was approved by the Ethics Committee of Hormozgan University of Medical Sciences (Ethical code: HUMS.REC.1395.037).

\section{Introduction:}

For rapid recovery, Propofol is an intravenous anesthetic widely used in outpatient and short-duration surgeries due (Miller et al., 2014). However, pain on injection was seen to cause discomfort in $45-75 \%$ of patients and several medications have been suggested that reduce the incidence and severity of pain during propofol injection. Various doses of lidocaine, ondansetron, metoclopramide, opiate, paracetamol, dexamethasone, pethidine, and ketamine reduce propofol-induced pain. Lidocaine is the most commonly used medication for pain relief after propofol injection. Bolus dose or lidocaine + propofol mixture is used to relieve pain (Dubey \& Prasad, 2003). The Lidocaine is a local anesthetic that reduces pain through peripheral nerve blocks (PNBs) by stimulating peripheral nerve membranes and incidence of pain was reported as $32-48 \%$ on patients who were injected with lidocaine (Mohammadzadeh et al., 2011). Paracetamol (acetaminophen, n-acetyl-p-amino-phenol) is a nonopioid antipyretic safe and effective analgesic reported fewer side effects than other medications (Amrimaleh et al., 2013). Acetaminophen has analgesic and antipyretic

\section{Abstract}

Propofol is an intravenous anesthetic widely used in outpatient and short-duration surgeries for rapid recovery. Pain during injection may cause discomfort in some patients. Several medications have been suggested that reduce the severity of pain during propofol injection. The present study aimed to compare the effect of intravenous injection of paracetamol, dexamethasone, pethidine, lidocaine, and ketamine on propofol post-injection pain in patients undergoing elective surgery, following a doubleblind randomized clinical trial on 306 patients aged from 18 to 65 who were candidates for elective surgery. Patients were divided into six groups each group consisted of $5^{1}$ individuals. Mean age of participants in this study was $31.9 \pm$ 9.5 out of which $209(68.3 \%)$ were males and 97 (31.7\%) were females. Lidocaine and paracetamol revealed the highest pain-free parameters among other groups. Pain severity was also less in lidocaine and dexamethasone groups than other groups. Finally, lidocaine was seen to be the most eff icacious analgesic in reducing pain from propofol injection and could be safely advised for propofol-induced pain relieve.

effects similar to aspirin but the action site and analgesic mechanism are not very much clear yet (Shoeibi et al., 2005). Dexamethasone is a corticosteroid used in several clinical trials to increase the duration of analgesia (Kakodkar, 2013). Pethidine is one of the most effective treatments for post-anesthetic pain and shivering (Wolfers, 1953). Ketamine is an anesthetic and noncompetitive N-methyl-D-aspartate (NMDA) receptor antagonist, low-dose ketamine can reduce pain (Kurdi et al., 2014; Alizadeh et al., 2015). Given the significant incidence of pain among patients, it is essential to reduce pain in the operating room and prepare the patients for surgery by reducing their mental stress. Many methods have been proposed to reduce propofol-induced pain. However, including advantages, each medication has some disadvantages. Thus, it felt a priority to identify a safe and usable method for analgesia induction in the operating room. The present study aimed to compare the effect of intravenous injection of paracetamol, dexamethasone, pethidine, lidocaine and ketamine on propofol postinjection pain in patients undergoing elective surgery in Bandar Abbas. 


\section{Methodology:}

This was a double-blind clinical trial. The statistical population consisted of all such patients who were referred for elective surgery under general anesthesia in Shahid Mohammadi Hospital in Bandar Abbas in 20152016. Inclusion criteria were no susceptibility to propofol, paracetamol, dexamethasone, pethidine, lidocaine and ketamine, cooperation and the ability to communicate with the research team, no underlying disease such as diabetes, hepatic disorders, cardiovascular disorders, no alcohol abuse, no opiate addiction, no chronic pain syndromes and thrombophlebitis, no intake of any analgesic and anesthetic. Patients above 65 years of age and unwillingness to participate were excluded from the study. Written consents were obtained from the patients. A convenient sampling method was used to select 306 patients aged between 18 to 65 with ASA I and II. The participants were selected using a random number table derived from Random Allocation Software and were randomly divided into six groups. Each group consisted of 51 patients. Information about the patients was recorded on a checklist including demographic variables (age, gender and BMI) ASA class and the main variable (pain severity).

After obtaining consent from the patients in a preoperative anesthetic visit, the project procedure and verbal scoring of response to pain severity were explained to the patients. Verbal descriptions of patients on pain severity were scored as follows. $\mathrm{o}=$ painless; $1=$ mild pain, positive response but no facial expression of pain, $2=$ moderate pain, positive response, behavioral symptoms of pain and a spontaneous pain report without asking; $3=$ severe pain, a strong positive response, facial expression of pain and crying. The patients were divided into six groups; group A: $40 \mathrm{mg}$ dose of $2 \%$ lidocaine diluted in normal saline, group B: $8 \mathrm{mg}$ dose of dexamethasone diluted in normal saline, group C: $0.2 \mathrm{mg} / \mathrm{kg}$ (body-weight) ketamine diluted in normal saline, group D: $25 \mathrm{mg}$ pethidine diluted in normal saline, group E: $100 \mathrm{mg}$ paracetamol (manufactured in Iran) diluted in normal saline, group F: $5 \mathrm{ml}$ of normal saline (placebo). The control group was also included in this study to compare pain severity in the five other groups in case of any problem in the administration of the medication and environmental conditions. Since no prodrug is currently used in many treatment centers prior to propofol injection, the inclusion of a control group in the study is justifiable for ethical issues. The study was double-blind since the patient delivered the card specif ic to this study to the nurse in the operating room. The nurses were also not aware of group classification. The nurse selected a card from the six cards based on the random number table derived from the Random Allocation Software and entered the card label in the patient record. The patients were transferred to the operating room beds. The catheter was inserted into the peripheral vein in the back of the hand using the catheter no. 20 (preferably non-dominant hand). The serum containing Ringer's solutions (the amount of fluid prescribed for the patient) was given to the patients. Non-invasive blood pressure, electrocardiogram, arterial oxygen saturation was measured and monitored in the operating room. Studied medications were diluted using normal saline by the anesthetist at the room temperature at equal volumes $(5 \mathrm{ml})$. The syringe was labeled as A, B, C, $\mathrm{D}, \mathrm{E}$ or $\mathrm{F}$ based on the studied groups. The desired medication was injected into the patient in 5 seconds by an investigator or the anesthetist who was aware of the type of medication (to treat the patient in case of any complication). After 30 seconds, $3 \mathrm{ml}$ of $1 \%$ propofol (30 $\mathrm{mg}$ ) was injected into the vein at a rate of $0.5 \mathrm{ml}$ per second. The injection was carried out by an anesthetist other than the investigator (who was not informed of the type of medication). He explicitly asked the patient about his pain or discomfort at the injection site and specified the patient's response as yes or no in the checklist. The pain severity was recorded in the checklist based on verbal descriptions. The general anesthesia procedure was continued (induction with propofol at $2 \mathrm{mg} / \mathrm{kg}$, mask ventilation of the lungs, administration of inhaled anesthetic or other opiates if necessary). The names and specifications of manu-facturing companies are as follows: Dexamethasone by Drugpakhsh Plant, Tehran, Iran; Apotel and pethidine by Exir Pharmaceutical Company, Boroujerd, Iran; lidocaine by Abourihan Pharmaceutical Company, Tehran, Iran; Ketamine by Allemagne Company, Germany; Propofol by B-Barun Metsungen AG.34209 Melsungen, Germany.

The collected data were entered into SPSS v.18. The data were transformed as mean, standard deviation and percentage and was statistically analyzed using tests for equality of means, 't-test', 'chi-square', 'Mann-Whitney U test' and 'Fisher's exact test'.

\section{Results:}

In total, 306 patients, divided into six groups, 209 (68.3\%) were males and 97 (31.7\%) were females. Mean age of the patients was $31.9 \pm 9 \cdot 5$. The range of age groups was (18-65). There was no statistically significant difference in the distribution of gender and BMI between the groups. These frequencies are reported in Table-1.

Comparison towards the frequency of pain in a normal saline group with other test groups showed statistically significant differences. There were no statistically significant differences in a number of painless cases between paracetamol and dexamethasone groups, paracetamol and ketamine groups, paracetamol and pethidine groups and pethidine and ketamine groups. Detailed information is given in Table-2. The highest painless and mild pain cases were reported in lidocaine 
treated group and the lowest painless and mild pain cases were reported in normal saline group. The details are reported in Table-3.

Table-1: Drug groups distribution among Gender and BMI

Table-2: Comparative analysis on frequency of pain in various drug groups

\begin{tabular}{llll}
\hline Group & \multicolumn{1}{c}{ Pain } & p value \\
\hline Normal saline & $51(100 \%)$ & o $(0 \%)$ & $<0.001$ \\
Paracetamol & $36(70.6 \%)$ & $15(29.4 \%)$ & \\
Normal saline & $51(100 \%)$ & o $(0 \%)$ & $<0.001$ \\
Dexamethasone & $21(41.2 \%)$ & $30(58.8 \%)$ & \\
Normal saline & $51(100 \%)$ & o $(0 \%)$ & $<0.001$ \\
Lidocaine & $3(5.9 \%)$ & $48(94.1 \%)$ & \\
Normal saline & $51(100 \%)$ & $0(0 \%)$ & $<0.001$ \\
Ketamine & $40(78.4 \%)$ & $11(21.65 \%)$ & \\
Normal saline & $51(100 \%)$ & $0(0 \%)$ & $<0.001$ \\
Pethidine & $41(80.4 \%)$ & $10(19.6 \%)$ & \\
Paracetamol & $36(70.6 \%)$ & $15(29.4 \%)$ & $\leq 0.03$ \\
Dexamethasone & $21(41.2 \%)$ & $30(58.8 \%)$ & \\
Paracetamol & $36(70.6 \%)$ & $15(29.4 \%)$ & $<0.001$ \\
Lidocaine & $3(5.9 \%)$ & $48(94.1 \%)$ & \\
Paracetamol & $36(70.6 \%)$ & $15(29.4 \%)$ & $\geq 0.363$ \\
Ketamine & $40(78.4 \%)$ & $11(21.65 \%)$ & \\
Paracetamol & $36(70.6 \%)$ & $15(29.4 \%)$ & $\geq 0.250$ \\
Pethidine & $41(80.4 \%)$ & $10(19.6 \%)$ & \\
Dexamethasone & $21(41.2 \%)$ & $30(58.8 \%)$ & $<0.001$ \\
Lidocaine & $3(5.9 \%)$ & $48(94.1 \%)$ & \\
Dexamethasone & $21(41.2 \%)$ & $30(58.8 \%)$ & $<0.001$ \\
Ketamine & $40(78.4 \%)$ & $11(21.65 \%)$ & \\
Dexamethasone & $21(41.2 \%)$ & $30(58.8 \%)$ & $<0.001$ \\
Pethidine & $41(80.4 \%)$ & $10(19.6 \%)$ & \\
Lidocaine & $3(5.9 \%)$ & $48(94.1 \%)$ & $<0.001$ \\
Ketamine & $40(78.4 \%)$ & $11(21.65 \%)$ & \\
Lidocaine & $3(5.9 \%)$ & $48(94.1 \%)$ & $<0.001$ \\
Pethidine & $41(80.4 \%)$ & $10(19.6 \%)$ & \\
Ketamine & $40(78.4 \%)$ & $11(21.65 \%)$ & $\geq 0.807$ \\
Pethidine & $41(80.4 \%)$ & $10(19.6 \%)$ & \\
\hline & & \\
\hline
\end{tabular}

There was a statistically significant relationship between gender and pain in the lidocaine group $(\mathrm{p}<0.008)$. However, this relationship was not statistically differ in othergroups Table-4.

\begin{tabular}{|c|c|c|c|c|c|}
\hline $\begin{array}{l}\text { Parace- } \\
\text { tamol }\end{array}$ & $\begin{array}{l}\text { Dexame } \\
\text { thasone }\end{array}$ & $\begin{array}{l}\text { Lido- } \\
\text { caine }\end{array}$ & $\begin{array}{l}\text { Keta- } \\
\text { mine }\end{array}$ & $\begin{array}{l}\text { Pethi } \\
\text { dine }\end{array}$ & $\begin{array}{l}\text { Normal p value } \\
\text { saline }\end{array}$ \\
\hline \multicolumn{6}{|c|}{ Gender: Male } \\
\hline $\begin{array}{l}33 \\
64.7 \% \\
\text { Gender: }\end{array}$ & $\begin{array}{l}36 \\
70.6 \% \\
\text { emale }\end{array}$ & $\begin{array}{l}35 \\
68.6 \%\end{array}$ & $\begin{array}{l}39 \\
76.5 \%\end{array}$ & $\begin{array}{l}34 \\
66.7 \%\end{array}$ & $\begin{array}{l}32 \\
62.7 \%\end{array}$ \\
\hline 18 & 15 & 16 & 12 & 17 & 19 \\
\hline $\begin{array}{l}35 \cdot 3 \% \\
\text { Total }\end{array}$ & $29.4 \%$ & $31.4 \%$ & $23.5 \%$ & $33.3 \%$ & $\geq 0.732$ \\
\hline $\begin{array}{l}51 \\
16.66 \%\end{array}$ & $\begin{array}{l}51 \\
16.66 \%\end{array}$ & $\begin{array}{l}51 \\
16.66 \%\end{array}$ & $\begin{array}{l}51 \\
16.66 \%\end{array}$ & $\begin{array}{l}51 \\
16.66 \%\end{array}$ & $\begin{array}{l}51 \\
16.66 \%\end{array}$ \\
\hline \multicolumn{6}{|c|}{ BMI (mean \pm SD) } \\
\hline $21.3 \pm 3.4$ & $25.2 \pm 2.6$ & $28.1 \pm 3.1$ & $25 \cdot 7 \pm 3.1$ & $26.3 \pm 3.2$ & $224.2 \pm 4.1 \geq 0.274$ \\
\hline
\end{tabular}

Table-3: Comparative chart showing pain severity in different drug groups ( $\mathrm{p}$ value $<0.001$ )

\begin{tabular}{lllll}
\hline Group & \multicolumn{2}{l}{ Pain severity } & & \\
& Painless & Mild & Moderate & Severe \\
\hline Paracetamol & $15(29.4 \%)$ & $31(60.8 \%)$ & $5(9.8 \%)$ & o (o\%) \\
Dexamethasone & $30(58.8 \%)$ & $15(29.4 \%)$ & $6(11.8 \%)$ & o (o\%) \\
Ketamine & $11(21.6 \%)$ & $14(27.5 \%)$ & $21(41.2 \%)$ & $5(9.8 \%)$ \\
Pethidine & $10(19.6 \%)$ & $33(64.7 \%)$ & $8(15.7 \%)$ & o (o\%) \\
Normal saline & o (o\%) & $1(2 \%)$ & $20(39.2 \%)$ & $30(58.8 \%)$ \\
\hline
\end{tabular}

Table-4: Relationship between gender and pain

\begin{tabular}{lllll}
\hline Group & Gender & \multicolumn{2}{c}{ Pain } & p value \\
& & Yes & No & \\
\hline Paracetamol & Male & $24(72.7 \%)$ & $9(27.3 \%)$ & $\geq 0.560$ \\
& Female & $12(66.7 \%)$ & $6(33.3 \%)$ & \\
Dexamethasone & Male & $16(44.4 \%)$ & $20(55.6 \%)$ & $\geq 0.463$ \\
& Female & $5(33.3 \%)$ & $10(66.7 \%)$ & \\
Lidocaine & Male & o (o\%) & $35(100 \%)$ & $\leq 0.008$ \\
& Female & $3(18.8 \%)$ & $13(81.3 \%)$ & \\
Ketamine & Male & $33(84.6 \%)$ & $6(15.4 \%)$ & $\leq 0.053$ \\
& Female & $7(58.3 \%)$ & $5(41.7 \%)$ & \\
Pethidine & Male & $28(82.4 \%)$ & $6(17.6 \%)$ & $\geq 0.618$ \\
& Female & $13(76.6 \%)$ & $4(23.5 \%)$ & \\
Normal saline & Male & $32(100 \%)$ & o (o\%) & --- \\
& Female & $19(100 \%)$ & o (o\%) & \\
\hline
\end{tabular}

Table-5: Comparison among mean age groups and report of pain in different drug groups

\begin{tabular}{lllll}
\hline Group Having pain & Without pain & Total & p value \\
& $\# M+S D$ & $\# M+S D$ & $\# M+S D$ &
\end{tabular}

Paracetm. $3629.86 \pm 8.16 \quad 15 \quad 27.40 \pm 6.03 \quad 51 \quad 29.13 \pm 7.62 \quad \geq 0.869$

Dexame. $21 \quad 32.47 \pm 15.7130 \quad 29.80 \pm 6.90 \quad 51 \quad 30.90 \pm 11.33 \geq 0.737$

Lidocaine $3 \quad 32.00 \pm 11.5348 \quad 35.89 \pm 13.43 \quad 51 \quad 35.66 \pm 13.26 \geq 0.663$

Ketamine $4030.27 \pm 7.24 \quad 11 \quad 30.18 \pm 13.54 \quad 51 \quad 30.25 \pm 8.80 \geq 0.809$ Pethidine $41 \quad 30.51 \pm 6.39 \quad 10 \quad 31.40 \pm 6.51 \quad 51 \quad 30.68 \pm 6.36 \geq 0.432$ Nor. Sal. $5135.00 \pm 9.76$ o $\quad---\quad 5135.00 \pm 9.76 \quad--$

\begin{tabular}{|c|c|c|c|c|}
\hline \multirow[t]{2}{*}{ Group } & \multirow{2}{*}{$\begin{array}{l}\text { BMI } \\
\text { Group }\end{array}$} & \multicolumn{2}{|l|}{ Pain } & \multirow[t]{2}{*}{ p value } \\
\hline & & Yes & No & \\
\hline \multirow[t]{3}{*}{ Paracetamol } & $19-25$ & $34(69.4 \%)$ & $15(30.6 \%)$ & \\
\hline & $25-30$ & $2(100 \%)$ & o $(0 \%)$ & \\
\hline & $>30$ & o $(0 \%)$ & o $(0 \%)$ & $\geq 0.352$ \\
\hline \multirow[t]{3}{*}{ Dexamethasone } & $19-25$ & $21(42 \%)$ & $29(58 \%)$ & \\
\hline & $25-30$ & o $(0 \%)$ & $1(100 \%)$ & \\
\hline & $>30$ & o $(0 \%)$ & $1(100 \%)$ & $\geq 0.398$ \\
\hline \multirow[t]{3}{*}{ Lidocaine } & $19-25$ & $3(6.7 \%)$ & $42(93 \cdot 3 \%)$ & \\
\hline & $25-30$ & o $(\mathrm{o} \%)$ & $5(100 \%)$ & \\
\hline & $>30$ & o $(0 \%)$ & $1(100 \%)$ & $\geq 0.809$ \\
\hline \multirow[t]{3}{*}{ Ketamine } & $19-25$ & $37(77.1 \%)$ & $11(22.9 \%)$ & \\
\hline & $25-30$ & $3(100 \%)$ & o $(0 \%)$ & \\
\hline & $>30$ & $\mathrm{o}(\mathrm{o} \%)$ & o $(0 \%)$ & $\geq 0.349$ \\
\hline \multirow[t]{3}{*}{ Pethidine } & $19-25$ & $38(79.2 \%)$ & $10(20.8 \%)$ & \\
\hline & $25-30$ & $2(100 \%)$ & o $(0 \%)$ & \\
\hline & $>30$ & $1(100 \%)$ & o $(0 \%)$ & $\geq 0.678$ \\
\hline \multirow[t]{3}{*}{ Normal saline } & $19-25$ & $50(100 \%)$ & o $(0 \%)$ & \\
\hline & $25-30$ & $1(100 \%)$ & о $(0 \%)$ & \\
\hline & $>30$ & o $(0 \%)$ & o $(0 \%)$ & \\
\hline
\end{tabular}


To evaluate the effect of age on a report of pain in each age group, mean age was compared in the groups with and without a report of pain. However, there was no statistically significant difference between age and report of pain in the groups (Table-5).

To determine the relationship between BMI and report of pain, the patients were divided into three groups of 19-25, 25-30 and above 30. However, no significant statistical relationship was found between these two factors (Table 6).

\section{Discussion:}

Pain on propofol injection can be a stressful experience for the patient. The chances of pain on propofol injection vary between $28 \%$ and $90 \%$ during anesthesia induction and it can also be severe. The chances of pain on propofol injection vary from $28 \%$ to $85 \%$ in children. The pain is more prevalent in younger children probably due to small vessels. There is no difference between the two genders in terms of incidence of pain. The pain from propofol injection is higher than other anesthetics. The incidences of pain during thiopental and methohexitone injection were reported as $7 \%$ and $12-64 \%$ respectively. The incidences of pain during midazolam and etomidate injection were respectively $1 \%$ and $24-48 \%$ (Mangar \& Holak, 1992; Valtonen et al., 1988; 1989; Cameron et al., 1992). Propofol is a phenol compound not similar to other anesthetics. It weighs as 1278 Daltons, a colorless and liquify at room temperature (Lee, 2010). Propofol was initially formulated as a mixture of $2 \%$ propofol + polyethylene castor oil $+8 \%$ ethanol. Later, it was formulated as $1 \%$ propofol $+16 \%$ chromophore. It was later reformulated as propofol + soybean oil to relieve pain from injection. Currently, propofol is available as $1 \%$ propofol + $10 \%$ soybean oil (Clarke et al., 1975). In the present study the effect of intravenous injection of paracetamol, dexamethasone, pethidine, lidocaine and ketamine was studied on pain from propofol injection. The highest painless and mild pain cases were reported in the lidocaine group (94.1\%) and the least cases were reported in normal saline $(0 \%)$ and pethidine $(19.6 \%)$ groups. The pain severity was less than other groups in the lidocaine group. However, pain severity was greater in normal saline and pethidine groups. In our study, the results showed that age, gender and BMI do not interfere with report of pain from propofol injection. The results of this study also showed a statistically significant difference in pain relief between normal saline and all test groups (dexamethasone, paracetamol, pethidine, lidocaine, and ketamine). This result was consistent with the results of the studies by Ahmad et al. (2013), Canbay et al. (2008), El-Radaideh, (2007), Euasobhon et al. (2016), Shoeibi et al. (2005) and Yadav et al. (2011). Lidocaine was more efficacious in relieving pain from propofol injection compared to other medications in this study. The difference between the lidocaine group and the other groups was statistically significant. This result was also strengthened the earlier results of Yadav etal. (2011), Ahmad et al. (2013), Canbay et al. (2008), Euasobhon et al. (2016), El-Radaideh, (2007), Vahid Alizadeh et al. (2016) and Jalota et al. (2011).

Dexamethasone was the second most efficacious medication for reducing pain from propofol injection in this study. In our study, three cases reported pain in the lidocaine group while 21 cases reported pain in the dexamethasone group. The difference between the two groups was statistically significant. The difference between dexamethasone and normal saline (all cases reported pain) was also statistically significant. Shoebi et al. (2005) reported that dexamethasone was more efficacious in reducing pain than normal saline. On the other hand, Ahmad et al. (2013) showed no significant difference in pain relief between lidocaine and dexamethasone groups. However, they found a signif icant difference between dexamethasone and normal saline. Yadav et al. (2011) also administered hydrocortisone to relieve pain but found no significant difference in pain relief. Their finding was not consistent with our present results. In the present study, 41 cases reported pain in the pethidine group and a statistically significant difference was found between pethidine and lidocaine in relieving pain. There was also a significant difference between lidocaine and normal saline groups in relieving pain. This difference was not statistically significant in comparison of pethidine with paracetamol and ketamine in relieving pain. Canbay et al. (2008) also showed that acetaminophen was significantly less efficacious than lidocaine but more efficacious than normal saline in relieving pain. El-Radaideh, (2007) also found that acetaminophen was less efficacious than lidocaine and fentanyl but more efficacious than normal saline in reducing pain. Ketamine and pethidine were also investigated in our study. These medications were less eff icacious in reducing pain severity than other groups but more efficacious than normal saline in reducing pain. Euasobhon et al. (2016) showed that although ketamine and pethidine did not noticeably reduce pain severity they were significantly more efficacious than normal saline in reducing pain in a meta-analysis. Their results strengthen our results of the present study. The findings of this study showed no significant relationship between the occurrence of pain and gender except for the lidocaine group. The relationship between the occurrence of pain and gender was only signif icant in the lidocaine group. The relationship between the incidence of pain and age was not significant in any group in our study it support the study of Shoebi et al. (2005). In the present study, we found no significant relationship between BMI and the incidence of pain in any group which resembles the findings of Canbay et al. (2008). 


\section{Conclusion:}

Lidocaine, dexamethasone, and paracetamol were more efficacious than other studied medications for pain relief in our study. Lidocaine also had the highest number of painless cases. Since propofol is used to induce anesthesia in a wide range of surgeries, it is suggested to administer lidocaine as a suitable anesthetic to reduce pain from propofol injection. However, it is recommended to conduct more studies with a larger sample size to examine the effects of other medications on the pain caused by propofol injection. According to the findings of our study and some of the earlier referred studies, it is recommended to administer lidocaine as an efficacious anesthetic to reduce the pain caused by propofol injection.

\section{Acknowledgment:}

We are grateful to all those people who helped us in this project, especially the respected professors, and staff of the Anesthesiology Department of Shahid Mohammadi Hospital in Bandar Abbas.

\section{References:}

Finnbogadóttir, H., Dykes., A. \& Wann-Hansson, C. (2014): Prevalence of domestic violence during pregnancy and related risk factors: a cross-sectional study in southern Sweden. BMC Women's Health., 14(63):1-13.

Gee, R., Mitra, N., Wan, F., Chavkin, D. \& Long, J. (2009): Power over parity: intimate partner violence and issues of fertility control. Am. JObstet Gynecol., 201(2):1481-1487.

Jamali, S. \& Javadpour, S. (2016): The Impact of Intimate Male Partner Violence on Women's Sexual Function: A Study in Iran. J. Clin. Diagn. Res., 10(12):29-33.

James, L., Brody, D. \& Hamilton, Z. (2013): Risk factors for domestic violence during pregnancy: a meta-analytic review. Violence Vict., 28(3):359-380.

James, D., Steer, P., Weiner, C. \& Gonik, B. (2010): High-risk pregnancy: management options. Pub. by: Saunders, Elsevier. p. 1504.

Jamshidimanesh, M., Soleymani, M., Ebrahimi, E. \& Hosseini, F. (2013): Domestic violence against pregnant women in Iran. J. Family Reprod. Health., 7(1):7-10.

Amrimaleh, P., Alijanpour, E., Zabihi, A., Attarzadeh, H., Shirkhani, Z., Rezaee, B., Rezaee, B. (2013): Comparison of Analgesic Effect of Intravenous Paracetamol plus Meperidine and Meperedine alone on Postoperative Pain after Elective Cesarean.J.Anesth. Pain., 4(1):1-7.

Cameron, E., Johnston, G., Crofts, S. \& Morton, N.S. (1992): The minimum effective dose of lignocaine to prevent injection pain due to propofol in children. Anaesthesia. 47(7):604-6o6.

Canbay, O., Celebi, N., Arun, O., Karagöz, A.H., Saricaoglu, F. \& Özgen, S. (2008): Efficacy of intravenous acetaminophen and lidocaine on propofol injection pain. $\mathrm{Br} J$ Anaesth., 100(1):95-98.
Clarke, R.S., Dundee, J.W., Garrett, R.T., McArdle, G.K., Sutton, J.A (1975): Adverse reactions to intravenous anaesthetics: a survey of 100 reports. Br JAnaesth. 47(5):575-585.

Dubey, P.K. \& Prasad, S.S. (2003): Pain on injection of propofol: the effect of granisetron pretreatment. Clin JPain., 19(2):121-124.

El-Radaideh, K.M. (2007): Effect of pretreatment with lidocaine, intravenous paracetamol and lidocaine-fentanyl on propofol injection pain: comparative study. Rev Bras Anestesiol. 57(1):32-38.

Euasobhon, P., Dej-arkom, S., Siriussawakul, A., Muangman, S., Sriraj, W., Pattanittum, P. \& Lumbiganon, P. (2016): Lidocaine for reducing propofol-induced pain on induction of anaesthesia in adults. Cochrane Database Syst Rev., 2:CDoo7874.

Kakodkar, P.S. (2013): Routine use of dexamethasone for postoperative nausea and vomiting: the case for. Anaesthesia. 68(9):889-891.

Kurdi, M.S., Theerth, K.A. \& Deva, R.S. (2014): Ketamine: Current applications in anesthesia, pain, and critical care. Anesth. Essays Res., 8(3):283-290.

Jalota, L., Kalira, V., George, E., Shi, Y.Y., Hornuss, C., Radke, O., Pace, N.L. \& Apfel, C.C. (2011): Prevention of pain on injection of propofol: systematic review and meta-analysis. BMJ., 342::d1110.

Lee, S.K. (2010): Pain on injection with propofol. Korean I Anesthesiol., 59(5):297-298.

Mangar, D. \& Holak, E.J. (1992): Tourniquet at $50 \mathrm{~mm} \mathrm{Hg}$ followed by intravenous lidocaine diminishes hand pain associated with propofol injection. Anesthesia E Analgesia., 74(2):250252.

Miller, R.D., Eriksson, L.I., Fleisher, L.A., Wiener-Kronish, J.P., Young, W.L. (2014): Miller's Anesthesia. Pub. by: Elsevier Health Sciences. p. 3576.

Mohammadzadeh, A., Haghighi, M., Amir-alavi, S., Naderi-nabi, B., Nekoofard, M. \& Abad, M. (2011): A Comparison of Effects of Alfentanil, Magnesium Sulfate and Ketamin on Reduction the Pain during Propofol Injection. J. Anesthesiol. Pain, 22(5):52-58.

Shoeibi, G., Khajavi Khan, J., Movafegh, A. (2005): Assessment and comparing the efficacy of Propofol pretreatment with Dexamethasone in prevalence and severity if its pain on Injection. Tehran Uni. Med.J., 63(1):55-6o.

Valtonen, M., Iisalo, E., Kanto, J. \& Tikkanen, J. (1988): Comparison between propofol and thiopentone for induction of anesthesia in children. Anaesthesia., 43(8):696-699.

Valtonen, M., Iisalo, E., Kanto, J. \& Rosenberg, P. (1989): Propofol as an induction agent in children: pain on injection and pharmacokinetics. Acta Anaesthesiol Scand., 33(2):152-155.

Wolfers, P. (1953): Intravenous Pethidine in anesthesia. Brit. J. Anccsth. 25:244-249.

Yadav, M., Durga, P. \& Gopinath, R. (2011): Role of Steroids in Prevention of Pain on Propofol Injection. JAnaesthesiol. Clin. Pharmacol., 27(4):470-474.

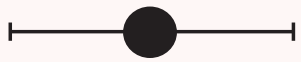

